\title{
Bioactive glass engineered coatings for Ti6Al4V alloys: Influence of strontium substitution for calcium on sintering behaviour
}

\author{
Nasrin Lotfibakhshaiesh ${ }^{1}$, Delia S. Brauer, ${ }^{2,}$, Robert G. Hill ${ }^{2}$ \\ ${ }^{1}$ Imperial College, Department of Materials, Exhibition Road, London SW7 2AZ, UK \\ ${ }^{2}$ Barts and The London, Unit of Dental Physical Sciences, Mile End Road, London E1 4NS, UK
}

*Corresponding author. Tel.: +44 (0)207 882 7409; fax: +44 (0)207 882 7979. E-mail address: d.brauer@qmul.ac.uk. 


\section{Abstract}

Bioactive glass coatings with thermal expansion coefficients matched to Ti6Al4V alloys have been designed, and glasses based on the multicomponent system 49.96 $\mathrm{SiO}_{2}-7.25 \mathrm{MgO}-3.30 \mathrm{Na}_{2} \mathrm{O}-$ 3.30 $\mathrm{K}_{2} \mathrm{O}-3.00 \mathrm{ZnO}-1.07 \mathrm{P}_{2} \mathrm{O}_{5}-32.62 \mathrm{CaO}$ (mol\%) with $0,10,25,50,75$ and $100 \%$ of calcium oxide replaced by strontium oxide have been produced by a melt-quench route. Sintering behaviour has been characterised by differential scanning calorimetry, X-ray diffraction and scanning electron microscopy. Glass transition and crystallisation temperatures and their respective activation energies were determined; extrapolated onset values for these parameters have been determined in order to optimise the sintering temperature for producing amorphous coatings. Amorphous coatings have been produced which showed good adhesion to the alloy with the exception of the $100 \%$ Sr substituted coating. Substituting strontium for calcium reduced the glass transition temperature and lowered the activation energy for crystallisation whilst increasing the onset temperature of crystallisation. The mixed calcium/strontium glasses exhibit a larger processing window, which favours sintering without crystallisation occurring and obtaining amorphous well sintered coatings. However, complete substitution favours crystallisation and reduces the processing window.

\section{PACS}

61.05.cp, 65.60.+a,81.05.Kf, 87.85.J-

\section{Keywords}

X-ray diffraction, Thermal properties, Biomaterials B124, Coatings, Strontium 


\section{Introduction}

The requirement for prosthetic metallic implants continues to grow as people live longer and more people are injured from physical activity and physical trauma. Metal alloys used in hip replacements do not bond or integrate well with bone, and therefore bioactive coatings are of interest to improve implant performance. Bioactive glasses, which degrade in the human body forming an apatite surface layer, were shown to form an integrated bond to mineralised tissue $[1,2]$. They were first developed by Hench in the late 1960s, and one intended application was for coating the femoral stem of hip prostheses for cementless fixation. The purpose of the bioactive glass coating was to promote osseointegration in order to provide a bond between prosthesis and bone. The procedure involved dip coating the prosthesis into the molten liquid glass at very high temperatures. However, satisfactory adhesion between the metal prosthesis and the bioactive glass was not achieved as a result of the large difference in the thermal expansion coefficient, TEC, between the glass and the metal [3].

The importance of matching the TEC of the glass to the alloy used for prosthesis has largely been neglected in most of the published studies of bioactive glass coatings on alloys used for medical prostheses. The studies by Gomez-Vega et al. [4,5] are a notable exception: the authors clearly recognise the importance of matching the TEC of the glass to the metal in their studies of bioactive glass coatings on Ti6Al4V alloys. Furthermore, Gomez-Vega et al. advocated an approach based on enamelling involving the sintering of glass particles at a temperature between the glass transition and crystallisation onset of a deposited coating.

The commercially available $45 \mathrm{~S} 5$ bioactive glass $\left(\right.$ Bioglass $^{\circledR}$ ) consisting of $46.1 \mathrm{SiO}_{2}-2.5 \mathrm{P}_{2} \mathrm{O}_{5^{-}}$ $26.9 \mathrm{CaO}-24.4 \mathrm{Na}_{2} \mathrm{O}(\mathrm{mol} \%)$ has not only too high a TEC for enamelling Ti6Al4V $\left(16 \times 10^{-6} \mathrm{~K}^{-1}\right.$ and 8$10 \times 10^{-6} \mathrm{~K}^{-1}$, respectively) but also crystallises almost immediately after heating above the glass transition temperature [6], which has two major drawbacks: a) it inhibits sintering by a high temperature viscous flow mechanism and b) any crystallisation will inherently reduce bioactivity in vivo. Both these aspects were recognised by Gomez-Vega et al. [4,5], and they clearly set out most but not all of the material design requirements and processing conditions for successfully producing bioactive glass coatings on Ti6Al4V alloy. These are summarised as follows:

i) A TEC match of the glass to the Ti6Al4V alloy; we propose that the glass has a slightly higher TEC than the metal substrate so the coating is in compression. 
ii) The coating must be sintered below the $\alpha \rightarrow \beta$ phase transition temperature of Ti6Al4V alloy $\left(\approx 980^{\circ} \mathrm{C}\right)$ in order not to compromise the mechanical properties and the fatigue life due to the large thermal expansion change in the alloy at this point.

iii) The coating must be sintered well below the onset temperature for crystallisation; we propose that ideally the working range of the glass $\left(\mathrm{T}_{\mathrm{c}}-\mathrm{T}_{\mathrm{g}}\right)>100^{\circ} \mathrm{C}$.

iv) The coating must be sintered in an oxygen free (i.e. vacuum or noble gas) environment to prevent excessive oxidation of the Ti6Al4V alloy and remove any bubbles from the interfacial region and bulk of the coating.

v) The glass must be bioactive (form a HCA layer in SBF in less than 4 weeks according to ISO 23317).

Gomez Vega et al. [4,5] successfully produced well bonded glass coatings on Ti6Al4V alloys; however, they failed to recognise the importance of the network connectivity (NC) [7] of the glass in determining bioactivity, with the result that their coatings which bonded to Ti6Al4V had far from optimal bioactivity [5]. The authors resorted to adding hydroxyapatite or 45S5 Bioglass ${ }^{\circledR}$ particles to the coating surface to alleviate this problem, and more recently they have advocated the use of bi-layer coatings $[8,9]$.

The bioactivity of glasses is strongly correlated with their $\mathrm{NC}[7,10]$ defined here as the average number of bridging oxygens (BOs) per silicon in the glass network. The network connectivity may be calculated according to Hill [7], but it is now recognised that phosphate in bioactive glasses does not form part of the silicate network $[10,11]$ and is thought to exist as a distinct orthophosphate droplet phase [12], and due allowance must be made for this in the calculation of NC as well as in the calculation of the TEC. We assume that by analogy with sodium borosilicate glasses of low borate content, such as Pyrex ${ }^{\mathrm{TM}}$, the TEC of the glass is determined solely by the matrix silicate phase.

Recently Tilocca et al. [13-15] have simulated the structure of bioactive glasses using molecular dynamics modelling and emphasised the importance of the fragmented and discontinuous nature of the silicate network. They have also looked at the structural role of phosphate and found evidence for glasses with greater than $5 \mathrm{~mol} \% \mathrm{P}_{2} \mathrm{O}_{5}$ exhibiting amorphous phase separation into a silica rich and phosphate rich phase [15]. This was confirmed by solid-state ${ }^{31} \mathrm{P}$ nuclear magnetic resonance (NMR) experiments, which showed an orthophosphate phase for all phosphate contents when $\mathrm{NC}<2.5$ $[10,11,16]$ 
Furthermore it is now recognised that $\mathrm{MgO}$ [17] and $\mathrm{ZnO}$ [18] can act not only as network modifying oxides (which will form non-bridging oxygens, NBOs), but also enter the silicate network in highly disrupted bioactive glass formulations (which will reduce the number of NBOs due to the formation of $\left[\mathrm{MgO}_{4}\right]^{2-}$ complexes which require cations such as $\mathrm{Na}^{+}$or $\mathrm{Ca}^{2+}$ to charge balance). This, too, must be allowed for in the calculation of $\mathrm{NC}$, although it is difficult to predict the amount of $\mathrm{Mg}$ or $\mathrm{Zn}$ entering the network without structural investigations by e.g. solid-state NMR. $\mathrm{Mg}^{2+}$ and $\mathrm{Zn}^{2+}$ cations have similar ionic radii $\left(0.78 \AA\right.$ for $\mathrm{Mg}^{2+}$ and $0.83 \AA$ for $\left.\mathrm{Zn}^{2+}\right)$ and have charge to size ratios that put them at the boundary between being classified as network modifying and intermediate oxides [19]. It is also important to note that if these two species act as intermediate oxides they will become incorporated into the silicate chain structure and will act in an analogous fashion to co-monomers in organic polymers to suppress crystallisation. This is a particularly attractive feature since highly disruptive bioactive glasses will generally crystallise readily.

As a general rule the bioactivity is negligible or extremely low in glasses with $\mathrm{NC}$ values above 2.4, and it increases as $\mathrm{NC}$ is reduced towards a value of 2.0 , which corresponds to a linear $\mathrm{Q}^{2}$ silicate structure where each silicon has on average two BOs and two NBOs [10]. Therefore an additional criterion for designing bioactive glass coatings is that the glass must have a $\mathrm{NC}<2.4$ and preferably as close to 2.0 as possible. In contradiction to the mechanisms proposed by Hench [2], it is important to note that dissolution and bioactivity are controlled by NC, and that the mechanism of dissolution and bioactivity involves little or no alkaline hydrolysis of Si-O-Si bonds, but instead involves the congruent dissolution of the glass as suggested by Hill [7]. This view is supported by unpublished experimental results which show the absence of a mixed alkali effect with regard to dissolution and bioactivity in mixed-alkali bioactive glasses, and the observation that the activation for alkali metal ion hopping from dielectric measurements is at least a factor of four higher than that for dissolution.

In order to facilitate sintering and aid processing of coatings, a large temperature difference between the glass transition temperature $\left(T_{g}\right)$ and the onset temperature for crystallisation $\left(T_{0}\right)$ is required in the differential scanning calorimetry (DSC) trace of a glass powder suitable for sintering. Fig. 1a shows the DSC trace of the well-known 45S5 Bioglass ${ }^{\circledR}$ composition, and the DSC trace for a glass that is much more suitable for sintering is shown in Fig. 1b. Fig. 1b shows a much larger temperature difference between $T_{g}$ and $T_{0}$, and this temperature difference we will refer to subsequently as the processing window. 
Crystallisation of bioactive glasses is widely regarded as being undesirable $[2,20,21]$ since crystallisation will occur predominantly at the surface of bioactive glass particles and will thus reduce the volume fraction of glass for viscous flow sintering. Furthermore, crystallisation inherently reduces bioactivity since crystal phases are in a lower energy state, the structure will be more tightly packed and the bonding will be stronger than the equivalent glass composition, and as a consequence the crystal phase will be less soluble.
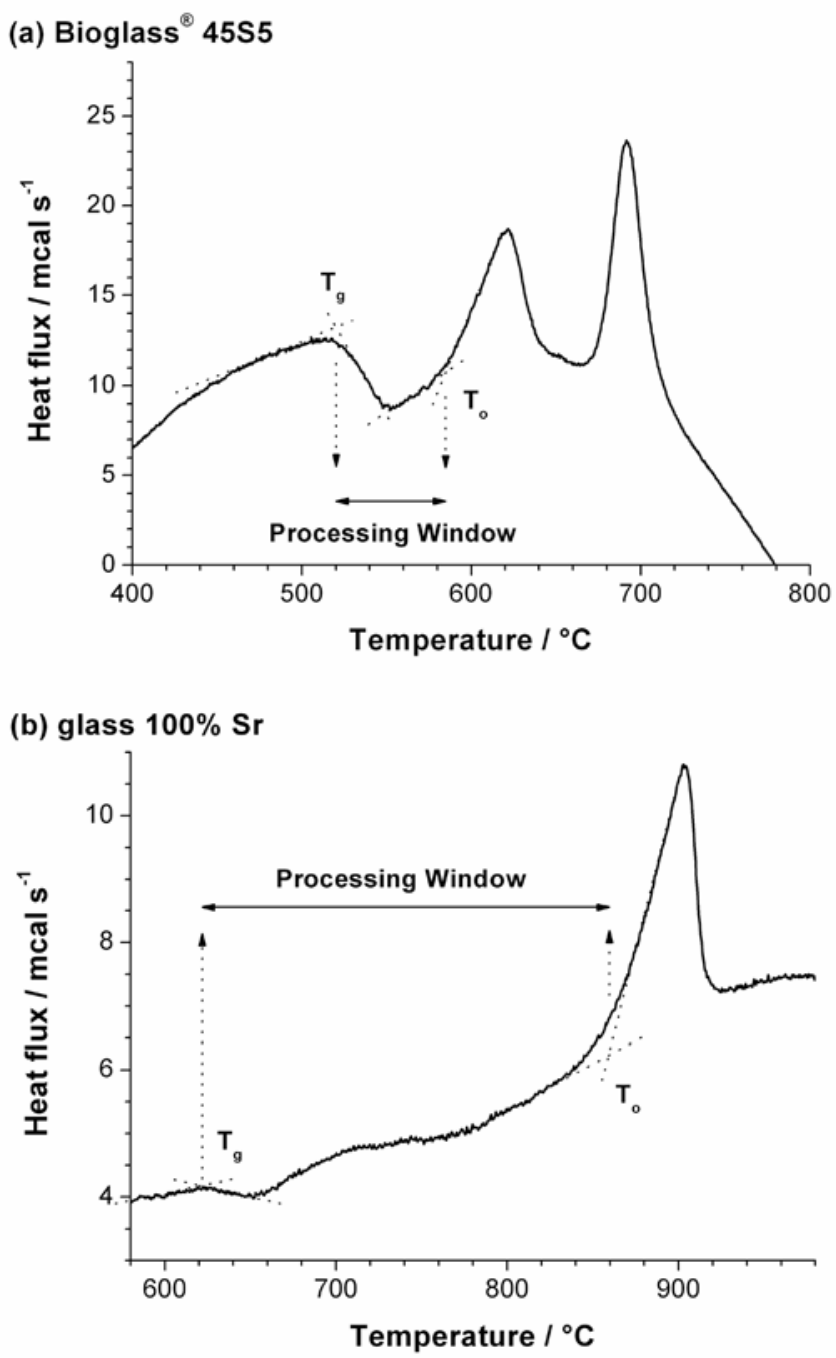

Figure 1: DSC traces with glass transition $\left(T_{g}\right)$ and onset peak crystallisation $\left(T_{\mathrm{o}}\right)$ temperatures and sintering window for (a) Bioglass ${ }^{\circledR} 45 \mathrm{~S} 5$ and (b) glass $100 \%$ Sr. (Dotted lines are drawn as a guide to the eye.)

We designed bioactive glass coatings based on the multicomponent system $49.46 \mathrm{SiO}_{2}-1.07 \mathrm{P}_{2} \mathrm{O}_{5^{-}}$ (32.62- $\times$ ) CaO- $\times$ SrO-7.25 MgO-3.00 ZnO-3.30 $\mathrm{Na}_{2} \mathrm{O}-3.30 \mathrm{~K}_{2} \mathrm{O}$ with thermal expansion coefficients matched to Ti6A14V alloys. Strontium was substituted for calcium in increasing amounts to provide 
localised release of $\mathrm{Sr}^{2+}$ from the glass, as it was shown that strontium has the ability to stimulate the formation of new bone tissue and decrease bone resorption, and strontium also is the active ingredient in a new drug for osteoporosis treatment $[22,23]$. We were interested to see how strontium substitution for calcium affects glass sintering and crystallisation behaviour.

\section{Experimental}

\subsection{Glass design}

The base glass composition, which is strontium-free (Table 1), was designed on the basis of its TEC calculated by means of Appen factors [24] and the calculated glass transition temperatures based on the paper by Andersson [25] with the objective of having a TEC close to the upper value for Ti6Al4V alloy of $10 \times 10^{-6} \mathrm{~K}^{-1}$ and having as low a $\mathrm{T}_{\mathrm{g}}$ as possible. For this purpose it is assumed that phosphorus is not part of the silicate glass network but exists as a separate orthophosphate phase dispersed in a silicate glass matrix phase. The level of phosphate is also low in these glasses and will not significantly contribute to the TEC. It is assumed that the TEC is determined by the composition of the silicate glass phase.

In order to suppress crystallisation with the aim of having a large sintering window compared with Bioglass $^{\circledR} 45 \mathrm{~S} 5$, it was decided to increase the number of network modifying oxides in the composition to suppress the onset temperature for crystallisation. This increases the entropy of mixing and increases the barrier for crystallisation as the energy barrier for atomic rearrangement is higher to form critical size nuclei. The study by Aida showed that the optical basicity of the oxides (numerical expression of the average electron donor power of the oxide species) contributed to the thermal stability of oxide glasses. The combination of a high optical basicity alkali metal oxide $\left(\mathrm{Na}_{2} \mathrm{O}-1.15\right)$ and a low optical basicity metal oxide $(\mathrm{ZnO}-0.95)$ causes a strong interaction in the glass and suppresses the movement of $\mathrm{Na}^{+}$and $\mathrm{Zn}^{2+}$ ions resulting in a high resistance to crystallisation [26].

Table 1: Glass compositions in mol\%.

\begin{tabular}{lcccccccc}
\multicolumn{1}{c}{ Glass } & $\mathrm{SiO}_{2}$ & $\mathrm{P}_{2} \mathrm{O}_{5}$ & $\mathrm{CaO}$ & $\mathrm{SrO}$ & $\mathrm{Na}_{2} \mathrm{O}$ & $\mathrm{K}_{2} \mathrm{O}$ & $\mathrm{MgO}$ & $\mathrm{ZnO}$ \\
\hline $0 \% \mathrm{Sr}$ & 49.46 & 1.07 & 32.62 & 0 & 3.30 & 3.30 & 7.25 & 3.00 \\
$10 \% \mathrm{Sr}$ & 49.46 & 1.07 & 29.36 & 3.26 & 3.30 & 3.30 & 7.25 & 3.00 \\
$25 \% \mathrm{Sr}$ & 49.46 & 1.07 & 24.47 & 8.16 & 3.30 & 3.30 & 7.25 & 3.00
\end{tabular}




$\begin{array}{lllllllll}50 \% \mathrm{Sr} & 49.46 & 1.07 & 16.31 & 16.31 & 3.30 & 3.30 & 7.25 & 3.00 \\ 75 \% \mathrm{Sr} & 49.46 & 1.07 & 8.16 & 24.47 & 3.30 & 3.30 & 7.25 & 3.00 \\ 100 \% \mathrm{Sr} & 49.46 & 1.07 & 0 & 32.62 & 3.30 & 3.30 & 7.25 & 3.00\end{array}$

Glasses incorporating both equal molar percentages of $\mathrm{Na}_{2} \mathrm{O}$ and $\mathrm{K}_{2} \mathrm{O}$ were produced. In addition, in order to reduce TEC and suppress crystallisation, $\mathrm{MgO}$ was also included, since it has been shown to act as an intermediate oxide and to suppress crystallisation [17]. $\mathrm{ZnO}$ was incorporated into the glass at $3 \mathrm{~mol} \%$ to further restrict the tendency towards crystallisation and to provide a small amount of $\mathrm{Zn}^{2+}$ release from the glass, which has well known bactericidal properties and is also important in wound repair and bone formation [27-29].

Finally $\mathrm{SrO}$ was included in the glass composition to provide localised $\mathrm{Sr}^{2+}$ release from the glass, as strontium is known to stimulate osteoblasts and inhibit osteoclasts [22,30,31]. In addition it has been shown recently that molar substitution of $\mathrm{Ca}$ by $\mathrm{Sr}$ in bioactive glasses increases the rate of dissolution of bioactive glasses by expanding the glass network and reducing the oxygen density of the glass [32].

\subsection{Glass synthesis}

The glass compositions studied are given in Table 1 and consist of one series of glasses where $\mathrm{SrO}$ is substituted for $\mathrm{CaO}$. The glasses were synthesised by mixing analytical grade silica (Prince Minerals Ltd., UK) with $\mathrm{CaCO}_{3}, \mathrm{SrCO}_{3}, \mathrm{MgO}, \mathrm{Na}_{2} \mathrm{CO}_{3}, \mathrm{~K}_{2} \mathrm{CO}_{3}$ and $\mathrm{ZnO}$ and $\mathrm{P}_{2} \mathrm{O}_{5}$ (all Sigma-Aldrich, UK) in the appropriate proportions, placing the mixed batch in a $300 \mathrm{~mL}$ platinum crucible and melting for 1.5 hours at $1450^{\circ} \mathrm{C}$ in an electric furnace (Lenton EHF 17/3, UK). The glass was fritted by pouring into water, dried at $120^{\circ} \mathrm{C}$ overnight, then ground in a vibratory puck mill (Gyro Mill, Glen Creston, UK) for 14 minutes and sieved through a $20 \mu \mathrm{m}$ sieve. Particle size of the fine powders for coatings was analysed using a laser particle size analyser (Cilas, UK).

\subsection{Glass characterisation}

The glass synthesised was analysed to understand how different percentages of $\mathrm{Sr}$ affect the glass properties. Techniques used were X-ray diffraction, differential scanning calorimetry and scanning electron microscopy. 


\subsection{1. $X$-ray diffraction $(X R D)$}

Each glass composition (as powder) and the coatings on Ti-alloy were studied using an X-ray powder diffractometer (Philips PW1700 series Automated Powder Diffractometer) with $\mathrm{CuK} \alpha$ radiation $(0.154056 \mathrm{~nm})$ at $40 \mathrm{kV} / 40 \mathrm{~mA}$ with a secondary graphite crystal monochromator. The spectrum was taken in the $2 \theta$ range of $10^{\circ}$ to $80^{\circ}$ with a step size of $0.04^{\circ}$.

\subsubsection{Differential scanning calorimetry (DSC)}

$50 \mathrm{mg}$ of each glass sample powder was put in an inert platinum crucible and was analysed by DSC using analytical grade alumina powder as a reference material. The experiments were carried out in air, using a Stanton-Redcroft DSC 1500 (PL Thermal Sciences, Epsom, UK) at a constant heating rate of $10 \mathrm{Kmin}^{-1}$ up to a maximum temperature of $1050^{\circ} \mathrm{C}$. The glass transition temperature $\left(\mathrm{T}_{\mathrm{g}}\right)$, the peak crystallisation temperature $\left(T_{p}\right)$ and the onset of crystallisation $\left(T_{0}\right)$ were determined for each glass. The processing window was calculated as the difference between $T_{0}$ and $T_{g}$. The tendency of the glasses to undergo surface nucleation was determined by performing DSC runs using two particle sizes: frit particles (approx. 1-2 mm) and fine powder $(<20 \mu \mathrm{m})$.

Activation energies for crystallisation, $E_{a}\left(T_{p}\right)$, were determined using the method outlined by Marrotta et al. [33]. The basis of the method is shown in equation 1:

$\ln (\beta)=\mathrm{E}_{\mathrm{a}} / \mathrm{RT}_{\mathrm{p}}+\mathrm{C}$

where $\beta$ is the reciprocal of the heating rate, $E_{a}$ is the activation energy of the process, $T_{p}$ is the crystallisation peak temperature, $\mathrm{R}$ the universal gas constant $\left(8.314 \mathrm{JK}^{-1} \mathrm{~mol}^{-1}\right)$, and $\mathrm{C}$ is a constant. The activation energy can be obtained from linear interpolation if $\ln (\beta)$ is plotted against $1 / T_{p}$ for varying heating rates $(1 / \beta)$. Five DSC heating rates of 5, 10, 15, 20 and $25 \mathrm{Kmin}^{-1}$ were used for the analysis. The gradient of the line of best fit $(m$ in $y=m x+c)$ is equal to $E_{a} / R$. The activation energies for the onset temperature for crystallisation and the glass transition temperature (which is often correlated with that for viscous flow) were calculated in a similar manner.

The activation energy plots were extrapolated to $\ln (\beta)=0$ (i.e. the $y$-axis intercept), corresponding to a heating rate of $1 \mathrm{Kmin}^{-1}$, to obtain values for the glass transition temperature and the onset temperature for crystallisation at a heating rate of $1 \mathrm{Kmin}^{-1}$. These values are important because during the isothermal sintering temperature of the coatings the heating rate is $0 \mathrm{Kmin}^{-1}$, and these values can be used to select the most appropriate sintering temperatures. 
The value of the activation energy for viscous flow is important as it gives a measure of the ability of the glass to flow during sintering. The lower this value the easier the glass will be expected to undergo viscous flow sintering. In contrast, the activation energy for the onset temperature of crystallisation gives a measure of the energy barrier to crystallisation, and a high value is preferred.

\subsubsection{Scanning electron microscope (SEM)}

Fusibility of the glass, appearance of the coatings and adherence of the coatings to the alloy were analysed using a scanning electron microscope (JEOL 5610, Jeol Ltd., UK) at $15 \mathrm{keV}$ with associated energy dispersive spectroscopy analysis (SEM-EDS). In order to look into the cross-section of the fabricated glass coating, the glass-coated alloy was mounted in a resin followed by grinding the crosssection with 1200 grit $\mathrm{SiC}$ paper and polishing it with $1 \mu \mathrm{m}$ diamond suspension. Line scans were performed for each glass cross-section sample with SEM-EDS. Line scan data was normalised by dividing the measurements by the average of each element. Diffusion coefficients were calculated from a least-squares fit of this complementary error-function (erfc) equation:

$\mathrm{N}=\mathrm{N}_{0} \operatorname{erfc}\left[\mathrm{x} /(2 \mathrm{Dt})^{0.5}\right]$

where $\mathrm{N}$ is the concentration of the element in question at distance $\mathrm{x}$ after time $\mathrm{t}$ from the concentration at $\mathrm{x}=0\left(\mathrm{~N}_{0}\right)$.

\subsection{Glass coatings}

Glass coatings on Ti6A14V were produced by an enamelling technique. A sedimentation method was used to deposit bioactive glass onto the Ti6Al4V alloy. $9.43 \mathrm{~g}$ of the selected glass powder (particle size $<20 \mu \mathrm{m}$ ) were dispersed in $25 \mathrm{~mL}$ of ethanol by stirring thoroughly. A Ti6Al4V piece $(5 \times 5 \times 1 \mathrm{~mm})$, which had been previously polished with $1 \mu \mathrm{m}$ diamond paper and cleaned in ethanol, was placed into the glass powder suspension. This was left in an oven at $80^{\circ} \mathrm{C}$ for $1.5 \mathrm{hrs}$ so that the glass powders were deposited on the metal substrate, producing a uniform surface. Confirming that the glass powder was totally settled, the specimen was introduced into a porcelain furnace (Centurion Quartz, Dentsply Ceramco, York, PA, USA) that was pre-heated to $250^{\circ} \mathrm{C}$. It was heated at a rate of $60 \mathrm{Kmin}^{-1}$ to $750^{\circ} \mathrm{C}$ followed by a $30 \mathrm{~min}$ hold at this temperature. This entire heating process was performed at $90 \mathrm{kPa}$ vacuum. 


\section{Results}

\subsection{Characterisation of glasses}

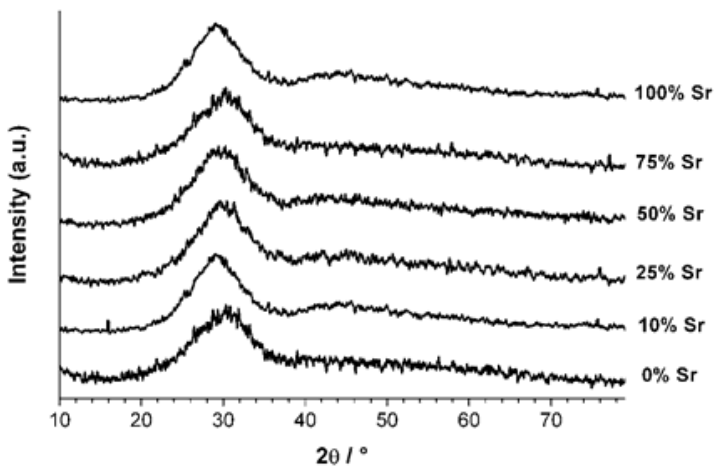

Figure 2: X-ray diffraction patterns of the glasses after quenching, drying and milling. (Curves smoothed by 5 -point adjacent average smoothing.)

All compositions were obtained in a glassy state with the amorphous structure being confirmed by XRD (Fig. 2). The maximum in the amorphous scattering shifts to smaller $2 \theta$ values with increasing strontium substitution. DSC traces of all the glasses exhibited peak crystallisation temperatures that shifted to higher temperatures with increasing particle size, shown in Fig. 3 for glass $50 \%$ Sr. Table 2 summarises the DSC results: extrapolated $\mathrm{T}_{\mathrm{g}}$ values show a very slight general decrease with increasing strontium substitution (Fig. $4 \mathrm{a})$ from $604^{\circ} \mathrm{C}(0 \% \mathrm{Sr})$ to $587^{\circ} \mathrm{C}(100 \% \mathrm{Sr})$. Crystallisation onset temperatures $\left(\mathrm{T}_{\mathrm{o}}\right.$; Fig. 4a) decrease from $808^{\circ} \mathrm{C}(0 \% \mathrm{Sr})$ to $753^{\circ} \mathrm{C}(100 \% \mathrm{Sr})$; however, the reduction is not linear: $\mathrm{T}_{\mathrm{o}}$ is approximately constant for the $0 \% \mathrm{Sr}$ and the $50 \% \mathrm{Sr}$ glasses but reduces significantly for the $100 \% \mathrm{Sr}$ glass to $753^{\circ} \mathrm{C}$. Processing windows (Fig. 4b) are between 200 and $240 \mathrm{~K}$ for all compositions apart from glass $100 \% \mathrm{Sr}$, which gave a processing window of $166 \mathrm{~K}$. The processing window seems to increase linearly for glasses with $0,25,50$ and $75 \%$ strontium substitution; however, the processing window of glass $10 \% \mathrm{Sr}$ does not follow the same trend and is considerably larger $(238 \mathrm{~K})$ than those of all other glasses in the series. Activation energies $\left(E_{a}\right)$ for glass transition and crystallisation temperatures are shown in Fig. 5. The activation energy for the glass transition temperature falls from $370 \mathrm{kJmol}^{-1}(0 \% \mathrm{Sr})$ to $325 \mathrm{kJmol}^{-1}(100 \% \mathrm{Sr})$ with increasing strontium content. Activation energy for $\mathrm{T}_{\mathrm{o}}$ decreased from $346 \mathrm{kJmol}^{-1}(0 \% \mathrm{Sr})$ to $208 \mathrm{kJmol}^{-1}$ $(100 \% \mathrm{Sr})$, and activation energy for $\mathrm{T}_{\mathrm{p}}$ decreases from $344 \mathrm{kJmol}^{-1}(0 \% \mathrm{Sr})$ to $280 \mathrm{kJmol}^{-1}(100 \% \mathrm{Sr}$, Fig. 5). Again, glass $10 \% \mathrm{Sr}$ does not follow the same trend and gives considerably higher activation energies. 


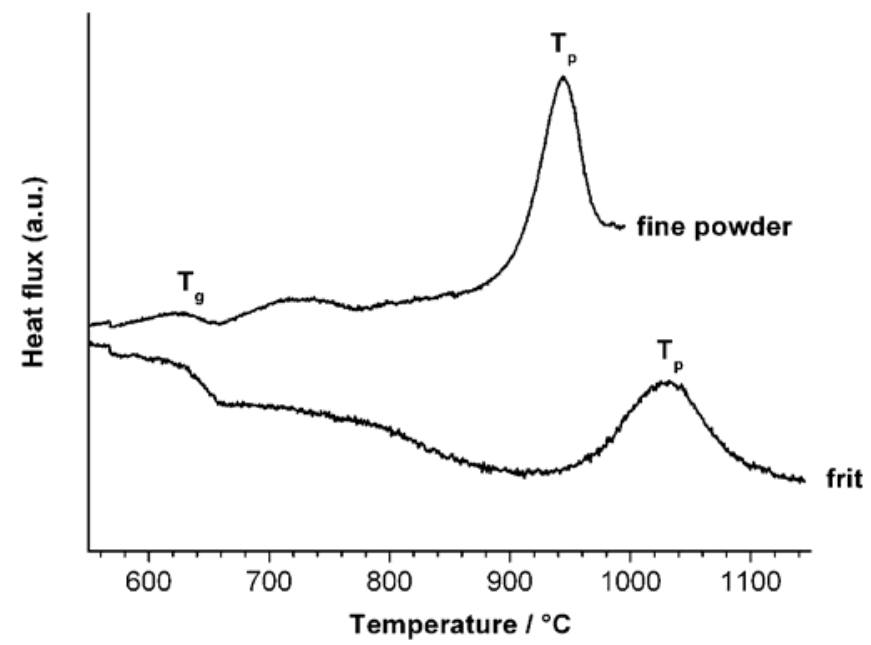

Figure 3: DSC traces of glass $50 \% \mathrm{Sr}$ for fine particles $(<20 \mu \mathrm{m})$ and frit (about $1-2 \mathrm{~mm})$ at a heating rate of $10 \mathrm{Kmin}^{-1}$.

Table 2: Summary of DSC results $\left(E_{\mathrm{a}}\right.$ : activation energy; $\mathrm{T}_{\mathrm{o}}-\mathrm{T}_{\mathrm{g}}$ : processing window; $\mathrm{T}_{\mathrm{g} 0}$ and $\mathrm{T}_{\mathrm{o} 0}$ are extrapolated values.)

\begin{tabular}{lcccccc} 
\%Strontium & $\begin{array}{c}\mathbf{T}_{\mathrm{g} 0} \\
\left({ }^{\circ} \mathrm{C}\right)\end{array}$ & $\begin{array}{c}\mathrm{E}_{\mathrm{a}}\left(\mathrm{T}_{\mathrm{g}}\right) \\
\left(\mathrm{kJmol}^{-1}\right)\end{array}$ & $\begin{array}{c}\mathrm{T}_{\mathrm{o0}} \\
\left({ }^{\circ} \mathrm{C}\right)\end{array}$ & $\begin{array}{c}\mathrm{E}_{\mathrm{a}}\left(\mathrm{T}_{\mathrm{o}}\right) \\
\left(\mathrm{kJmol}^{-1}\right)\end{array}$ & $\begin{array}{c}\mathrm{E}_{\mathrm{a}}\left(\mathrm{T}_{\mathrm{p}}\right) \\
\left(\mathrm{kJmol}^{-1}\right)\end{array}$ & $\begin{array}{c}\mathrm{T}_{\mathrm{o}}-\mathrm{T}_{\mathrm{g}} \\
\left({ }^{\circ} \mathrm{C}\right)\end{array}$ \\
\hline $0 \% \mathrm{Sr}$ & 604 & -370 & 808 & -346 & -344 & 204 \\
$10 \% \mathrm{Sr}$ & 580 & -350 & 818 & -527 & -413 & 238 \\
$25 \% \mathrm{Sr}$ & 597 & -351 & 806 & -238 & -295 & 209 \\
$50 \% \mathrm{Sr}$ & 590 & -320 & 807 & -246 & -233 & 217 \\
$75 \% \mathrm{Sr}$ & 572 & -340 & 793 & -245 & -300 & 221 \\
$100 \% \mathrm{Sr}$ & 587 & -325 & 753 & -208 & -280 & 166
\end{tabular}

\subsection{Characterisation of coatings}

XRD patterns of the coatings sintered at $750^{\circ} \mathrm{C}$ for $30 \mathrm{~min}$ are shown in Fig. $6 \mathrm{a}$, and they confirm that the coatings (except for $100 \% \mathrm{Sr}$ ) are amorphous. There is a small diffraction peak at $2 \theta=38^{\circ}$ for $10 \%, 25 \%$ and $50 \%$ strontium substituted glasses, but this corresponds to a diffraction line in the Ti6Al4V alloy and arises from the fact that X-rays are being diffracted from the alloy substrate beneath the glass coating. XRD of the $100 \% \mathrm{Sr}$ coating sintered at $800^{\circ} \mathrm{C}$ for $0.5 \mathrm{hrs}$ showed it to be highly crystalline (Fig. 6b). However, the crystal phases formed did not match any known crystalline phase. We therefore heat treated glass powder $(0 \% \mathrm{Sr}, 50 \% \mathrm{Sr}$ and $100 \% \mathrm{Sr})$ at $900^{\circ} \mathrm{C}$ and performed $\mathrm{x}-$ ray 
diffraction. Fig. 7 shows the XRD patterns of the heat treated glass powders at $900^{\circ} \mathrm{C}$; crystal phases are wollastonite $\left(\mathrm{CaSiO}_{3}\right.$, JCPDS $\left.27-0088 ; 0 \% \mathrm{Sr}\right)$ and strontium silicate $\left(\mathrm{SrSiO}_{3}\right.$, JCPDS 34-0099; $100 \% \mathrm{Sr}$ ). The peaks of the $50 \% \mathrm{Sr}$ composition did not match any known crystal phases, but are similar to the ones for $100 \% \mathrm{Sr}$ (strontium silicate) but shifted to higher $2 \theta$ values on the $\mathrm{x}$-axis.

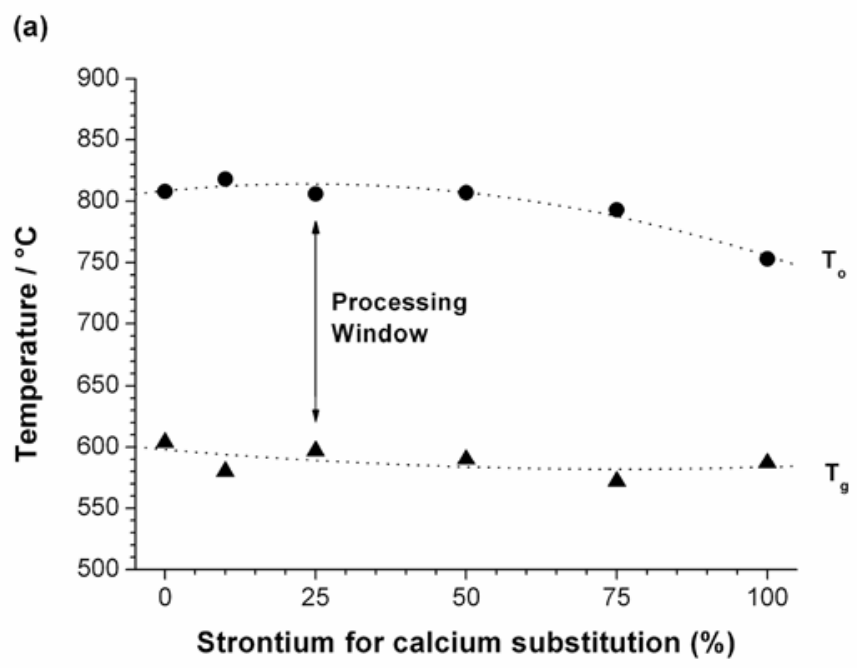

(b)

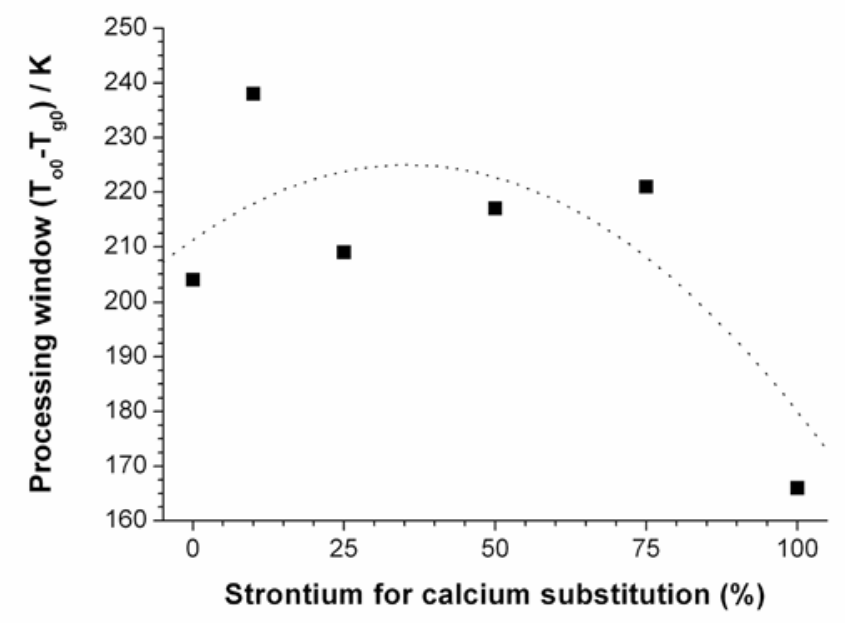

Figure 4: (a) Extrapolated values $\mathrm{T}_{\mathrm{g} 0}$ and $\mathrm{T}_{\mathrm{o} 0}$ and (b) processing window vs. strontium substitution for calcium (in \%). (Lines are drawn as a guide to the eye.)

An SEM micrograph of $50 \% \mathrm{Sr}$ glass powder is presented in Fig. 8a; particle size distribution values are shown in Table 3 . Mean diameter and $50 \%$ diameter differ considerably which suggests that the particle size distribution is non-Gaussian. The glass particles are angular with relatively sharp edges. The $50 \%$ particle size distribution was around $2.7 \mu \mathrm{m}$ which is in agreement with the SEM micrographs. 
Table 3: $\quad$ Particle size distribution values and mean for $0 \%, 10 \%, 50 \%$ Sr glass particles.

\begin{tabular}{ccccc} 
& Diameter 10\% & Diameter 50\% & Diameter 90\% & Mean diameter \\
Glass & $\boldsymbol{\mu m}$ & $\boldsymbol{\mu m}$ & $\boldsymbol{\mu m}$ & $\boldsymbol{\mu m}$ \\
\hline $0 \% \mathrm{mr}$ & 0.68 & 2.66 & 17.76 & 6.33 \\
$10 \% \mathrm{Sr}$ & 0.65 & 2.69 & 16.81 & 5.91 \\
$50 \% \mathrm{Sr}$ & 0.69 & 2.72 & 17.90 & 6.60
\end{tabular}

SEM investigation of $50 \% \mathrm{Sr}$ coatings after sintering contained few pores and little evidence of any remnants of the original glass particles (Fig. 8b). In addition, no cracks were observed on the surface of the coating sintered at $750^{\circ} \mathrm{C}$. It can be seen that the surface of $100 \% \mathrm{Sr}$ coating (Fig. 8c and d) contains pores and bubbles; at a low magnification several cracks were observed (Fig. 8c). SEM results (back scattered electron mode) presented in Fig. 9 show cross-sections of $50 \% \mathrm{Sr}$ and $100 \% \mathrm{Sr}$ glass coatings on Ti-alloy fired at $750^{\circ} \mathrm{C}$ : a $120 \mu \mathrm{m}$ thick glass coating can be seen to be well attached to the Ti6Al4V substrate for the $50 \% \mathrm{Sr}$ glass, whereas a gap and cracks are clearly observed between $100 \% \mathrm{Sr}$ glass and the Ti-alloy substrate. Delamination of the $100 \% \mathrm{Sr}$ coating occurred readily.

An elemental line scan was performed along the $50 \% \mathrm{Sr}$ glass coating and the results indicate that the coating was homogeneous as the elemental concentrations remained constant throughout the scan as (Fig. 10). Fig. 11 illustrates a line scan performed across the Ti-alloy/glass interface: The results show sigmoidal curves of decreasing $\mathrm{Ti}, \mathrm{Al}$ and $\mathrm{V}$ concentrations and sigmoidal curves of increasing concentrations for the elements comprising the glass composition over a distance of 5 to $10 \mu \mathrm{m}$ as expected. Diffusion coefficients are shown in Table 4.

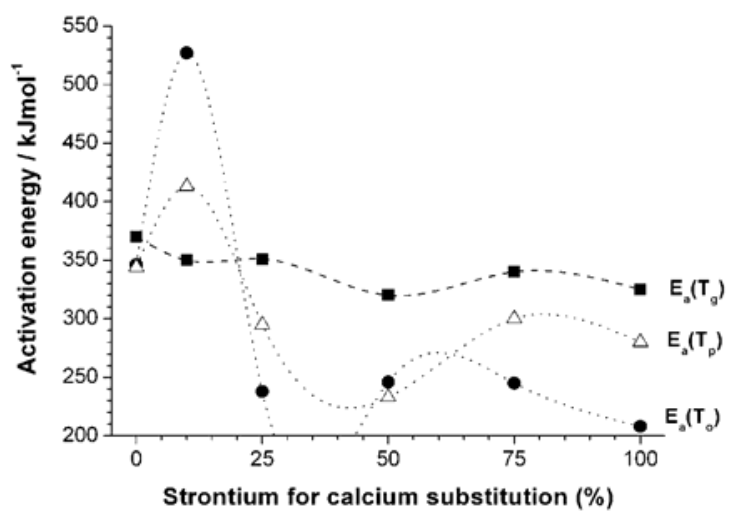

Figure 5: Activation Energy $\left(\mathrm{E}_{\mathrm{a}}\right)$ for glass transition $\left(\mathrm{T}_{\mathrm{g}}\right)$, onset peak crystallization $\left(\mathrm{T}_{\mathrm{o}}\right)$ and peak crystallization $\left(\mathrm{T}_{\mathrm{p}}\right)$ vs. strontium substitution for calcium (in \%). (Lines are drawn as a guide to the eye.) 
Table 4: Diffusion coefficients for 50\% strontium glass coated onto Ti6Al4V.

\begin{tabular}{cc} 
Element & $\mathbf{D}\left(\times \mathbf{1 \mathbf { 0 } ^ { - 1 5 }} \mathbf{m}^{\mathbf{2}} \cdot \mathbf{s}^{-1}\right)$ \\
\hline $\mathrm{Si}$ & Glass \\
$\mathrm{Na}$ & 6.49 \\
$\mathrm{~K}$ & 2.47 \\
$\mathrm{Ca}$ & 3.09 \\
$\mathrm{Sr}$ & 3.85 \\
$\mathrm{Mg}$ & 0.90 \\
$\mathrm{Zn}$ & 1.94 \\
$\mathrm{P}$ & 2.01 \\
$\mathrm{O}$ & 0.99 \\
\hline $\mathrm{Ti}$ & 9.36 \\
$\mathrm{~V}$ & \\
$\mathrm{Al}$ & \\
\hline
\end{tabular}

\section{Discussion}

\subsection{Characterisation of glasses}

Upon introduction of strontium into the glasses, the maximum of the amorphous halo in XRD patterns was found to shift progressively to smaller $2 \theta$ values (i.e. larger $\mathrm{d}$-spacing) with increasing strontium substitution, indicating an expansion of the glass network on incorporating strontium. Fredholm et al. [32] found a similar result with strontium substituted bioactive glass compositions along with a reduction in oxygen density and an increase in molar volume of the glass. The $\mathrm{Sr}^{2+}$ cation is slightly larger than $\mathrm{Ca}^{2+}$ cation $\left(1.16 \AA\right.$ for $\mathrm{Sr}^{2+}$ and $0.94 \AA$ for $\left.\mathrm{Ca}^{2+}\right)$ resulting in it attracting non-bridging oxygens less, which is thought to result in the expansion of the glass network.

The DSC traces of all the glasses exhibited peak crystallisation temperatures $\left(T_{p}\right)$ that shifted to higher temperatures with increasing particle size, indicating a surface induced nucleation process. This 
phenomenon appears to be a characteristic of bioactive glasses. It has been observed in a number of previous studies [10,34] and is related to the particle size effects on heat transfer [35].

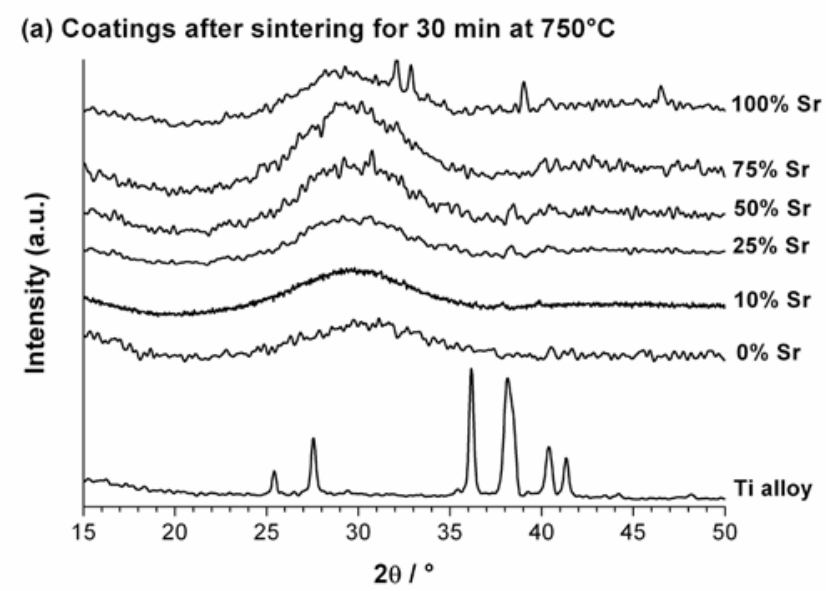

(b) Delaminated $100 \% \mathrm{Sr}$ coating heat treated at $800^{\circ} \mathrm{C}$

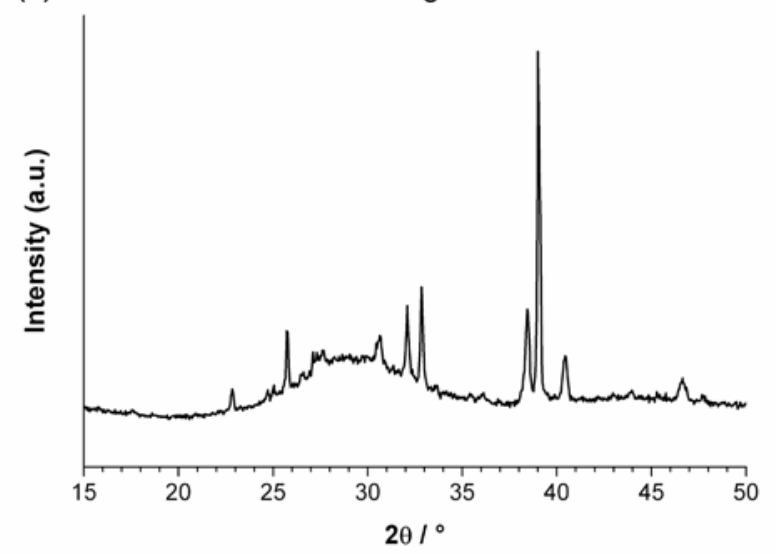

Figure 6: X-ray diffraction patterns of (a) bioactive glass coatings on Ti6Al4V alloy and uncoated Ti6A14V alloy as control (sample $10 \% \mathrm{Sr}$ was run using an increased count rate per step; all curves smoothed by 5-point adjacent average smoothing) and (b) a delaminated piece of $100 \% \mathrm{Sr}$ coating heat-treated at $800^{\circ} \mathrm{C}$.

Extrapolated $T_{g}$ values showed a slight general decrease with increasing strontium substitution. Similarly, activation energy for $\mathrm{T}_{\mathrm{g}}$ decreases with increasing strontium content. The activation energy for the glass transition temperature is often associated with that for viscous flow; a lower value is therefore likely to give rise to more efficient sintering for a given particle size distribution. Extrapolated $T_{0}$ values decrease with increasing strontium content, and activation energies for both $T_{o}$ and $T_{p}$ show a slight overall decrease with increasing strontium substitution. There are probably two factors influencing the results: On substituting $\mathrm{Sr}$ for $\mathrm{Ca}$ the glass network will become weaker, and it would be expected that the glass would be able to rearrange to the crystalline state more readily as a 
result. Opposing this is that incorporating $\mathrm{Sr}$ into an all $\mathrm{Ca}$ glass would be expected to increase the entropy of mixing and stabilise the disordered glass state. We would therefore expect the $100 \% \mathrm{Sr}$ substituted glass to crystallise more readily than any of the other glasses and to exhibit the lowest activation energies for $T_{g}, T_{0}$ and $T_{p}$. Our results show that this glass, indeed, crystallises at a significantly lower temperature than the other glasses and gives the smallest processing window.

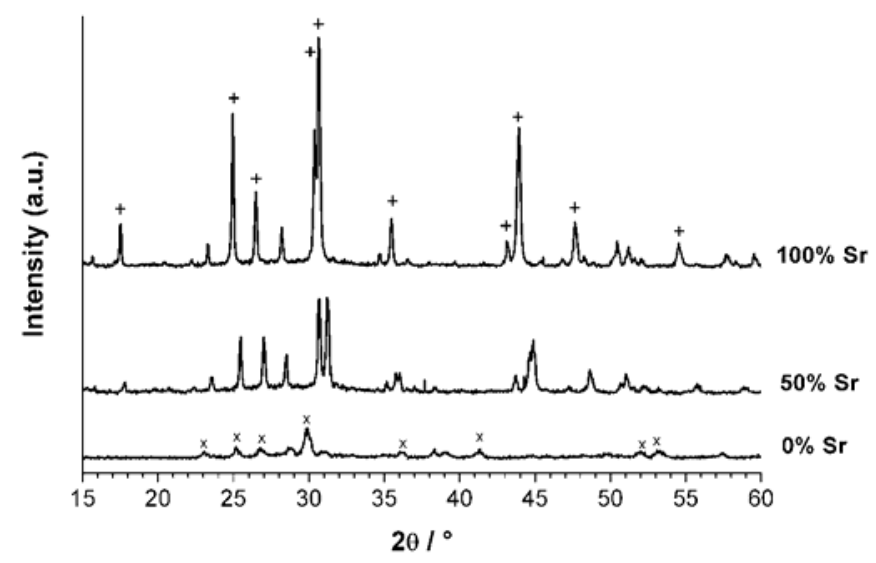

Figure 7: X-ray diffraction patterns of glass powder $0 \% \mathrm{Sr}, 50 \% \mathrm{Sr}$ and $100 \% \mathrm{Sr}$ heat-treated at $900^{\circ} \mathrm{C}$. Crystal phases are $\times$ wollastonite $\left(\mathrm{CaSiO}_{3}\right)$ and + strontium silicate $\left(\mathrm{SrSiO}_{3}\right)$.

All glasses in this series show a processing window significantly increased compared to Bioglass ${ }^{\circledR}$ 45S5 (Fig. 1a). This makes $45 \mathrm{~S} 5$ challenging to sinter above $\mathrm{T}_{\mathrm{g}}$ without some crystallisation occurring by conventional enamelling techniques. The processing window in our series increases slightly with increasing strontium substitution for calcium, but decreases by over $50 \mathrm{~K}$ for the $100 \%$ strontium substituted glass, largely as a result in the reduction in $\mathrm{T}_{0}$. We should therefore expect glass $100 \% \mathrm{Sr}$ to be the most difficult to sinter without crystallisation occurring.

\subsection{Characterisation of glass coatings on Ti- alloy}

According to the DSC results, of all the compositions studied the $100 \%$ strontium substituted glass should be the most difficult to sinter without crystallisation occurring. The sintering temperature of $750^{\circ} \mathrm{C}$ is very close to the crystallisation onset of glass $100 \% \mathrm{Sr}\left(753^{\circ} \mathrm{C}\right)$. However, lowering the temperature of sintering of the $100 \% \mathrm{Sr}$ glass resulted in opaque white but amorphous coating that had not sintered fully and scattered light as a result of a significantly high residual porosity in the coating (resuls not shown). XRD patterns of the coatings sintered at $750^{\circ} \mathrm{C}$ for $30 \mathrm{~min}$ show a typical amorphous halo except for glass $100 \% \mathrm{Sr}$, which gave crystalline peaks. Due to the small number and low intensity of the peaks, they were difficult to assign to a crystal phase. The delaminated $100 \% \mathrm{Sr}$ 
coating was therefore heat treated at $800^{\circ} \mathrm{C}$ for $30 \mathrm{~min}$; XRD showed it to be highly crystalline. However, the diffraction pattern did not match any known crystal phase, even if presence of elements from the alloy (titanium, aluminium or vanadium) was considered. This might be caused by the fact that the peaks are shifted slightly, most likely a result of the non-stoichiometry of the interfacial region or of formation of mixed cation phases in this multi-component system.
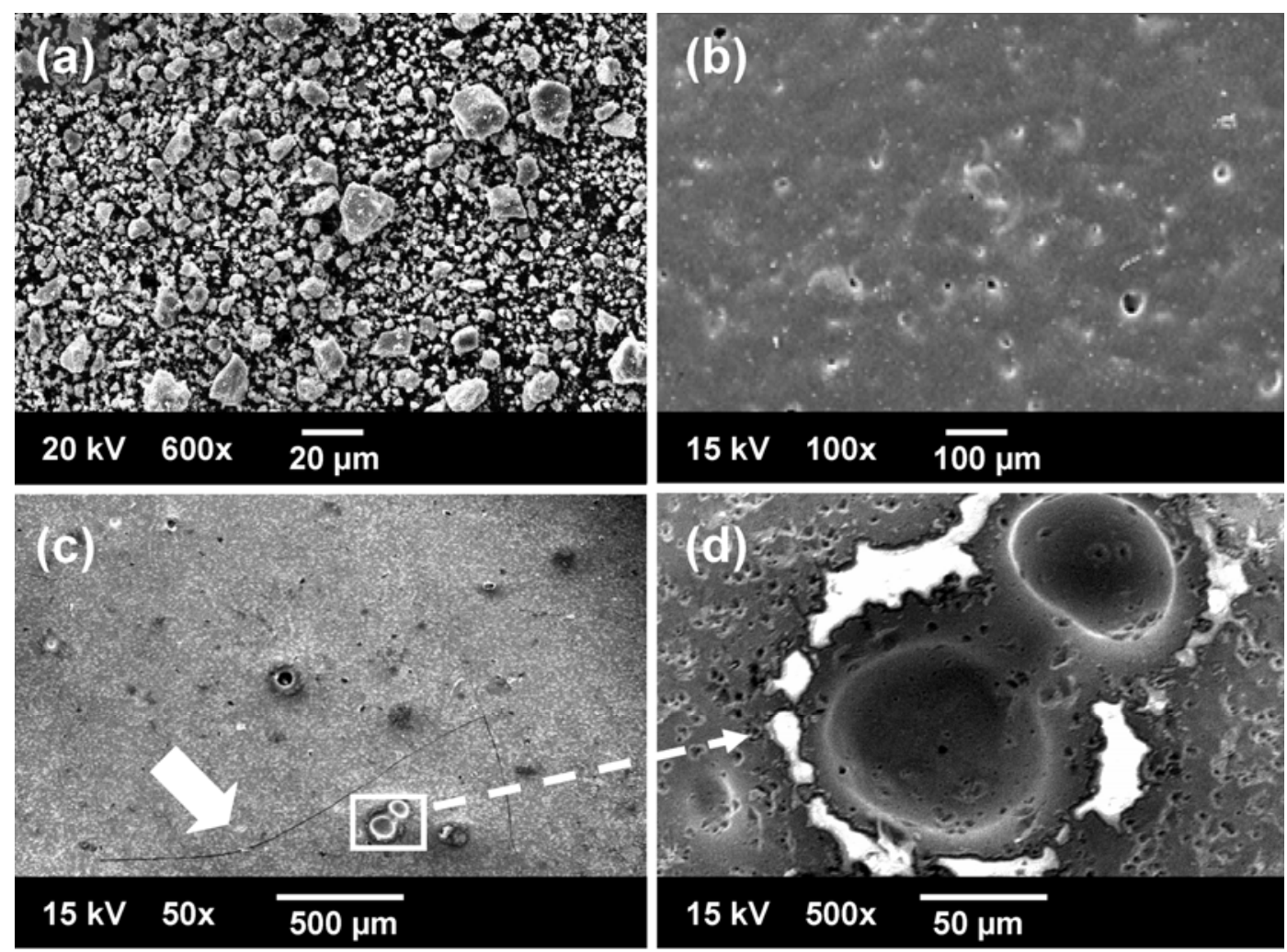

Figure 8: $\quad$ SEM micrograph (secondary electron mode) of (a) $50 \% \mathrm{Sr}$ glass powder, (b) $50 \% \mathrm{Sr}$ coated surface produced by enamelling, (c),(d) 100\% Sr coating with (c) overview with crack and pores and (d) bubbles and pores at higher magnification.

XRD patterns of glass powder heat treated at $900^{\circ} \mathrm{C}$ correspond to wollastonite (calcium silicate, $\mathrm{CaSiO}_{3}$, glass $\left.0 \% \mathrm{Sr}\right)$ and strontium silicate $\left(\mathrm{SrSiO}_{3}\right.$, glass $\left.100 \% \mathrm{Sr}\right)$. The pattern of heat treated $50 \% \mathrm{Sr}$ powder is most likely to be a mixed calcium strontium silicate, where the differences in ionic radii of $\mathrm{Sr}^{2+}$ and $\mathrm{Ca}^{2+}$ caused a shift in peak positions in XRD patterns compared to that of $\mathrm{SrSiO}_{3}$ (100\% Sr glass).

SEM micrographs of $50 \% \mathrm{Sr}$ sintered coatings shows that the thermal expansion of glass and Ti-alloy are well matched and that the viscous flow sintering process has occurred efficiently. Glass $100 \% \mathrm{Sr}$, on the other hand, is less suitable for coating using an enamelling technique due to the reduced 
processing window compared to the other glasses in the series as shown above. This results in partial crystallisation of the coating as well as poor adhesion and delamination.

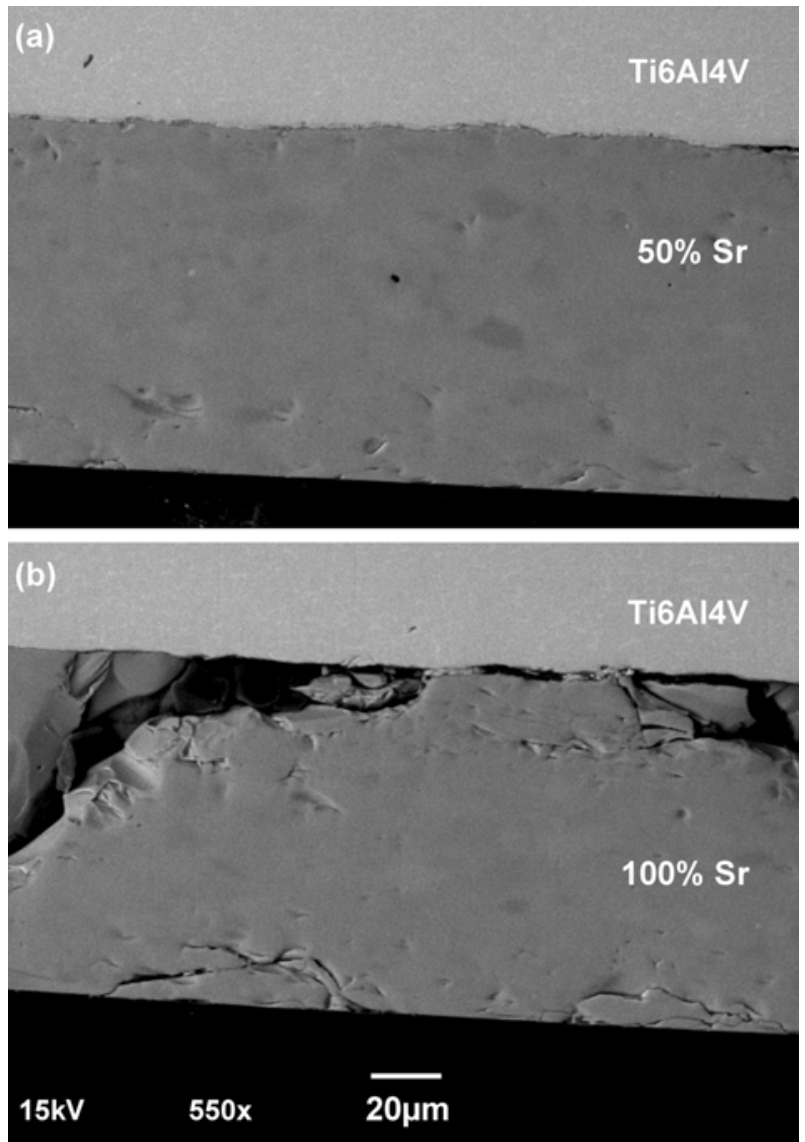

Figure 9: $\quad$ SEM images (backscattered electrons) of cross-sections of (a) $50 \% \mathrm{Sr}$ and (b) $100 \% \mathrm{Sr}$ coatings on Ti-alloy.

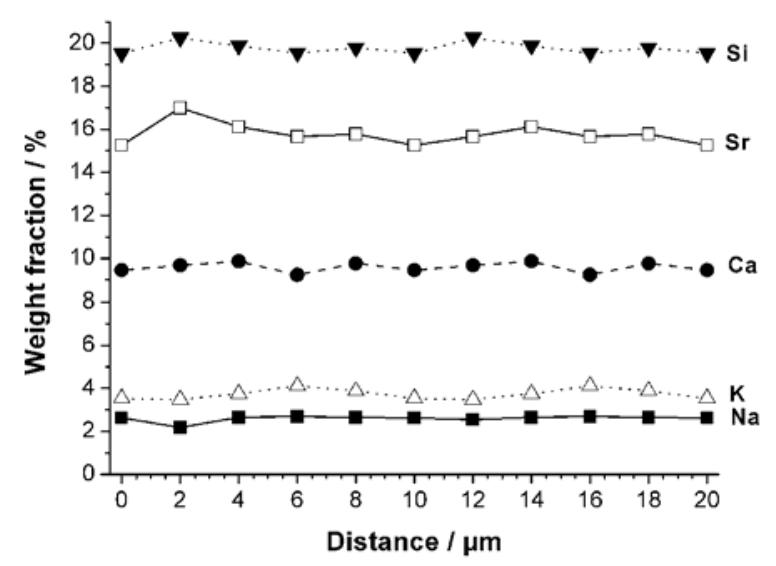

Figure10: Line scan profile of $50 \% \mathrm{Sr}$ glass coating.

The elemental line scan across the Ti-alloy/glass interface shows sigmoidal curves of decreasing $\mathrm{Ti}, \mathrm{Al}$ and $\mathrm{V}$ concentrations and increasing concentrations of the elements comprising the glass composition. 
A sigmoidal curve represents a classical diffusion profile in both alloy and glass composition: Diffusion rates of the alloy species ( $\mathrm{Ti}, \mathrm{Al}$ and $\mathrm{V}$ ) dropping off to zero around 5 to $10 \mu \mathrm{m}$ into the coating. This can be reduced further by reducing the sintering temperature and/or time.

SEM and XRD characterisation of the coatings confirmed a coherent interface between Ti6Al4V and glass, with no obvious crystallisation at the interface, and no Al, Ti or V was detected in the glass away from the interfacial region. There were very few pores or bubbles in the sintered coatings indicating that the sintering had been efficient.
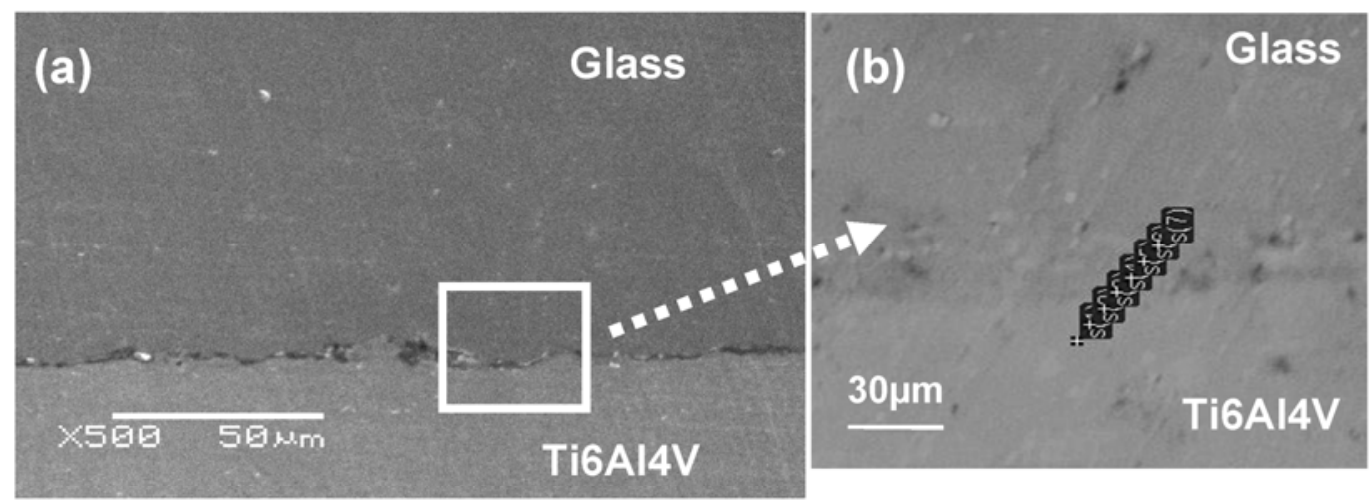

(c)

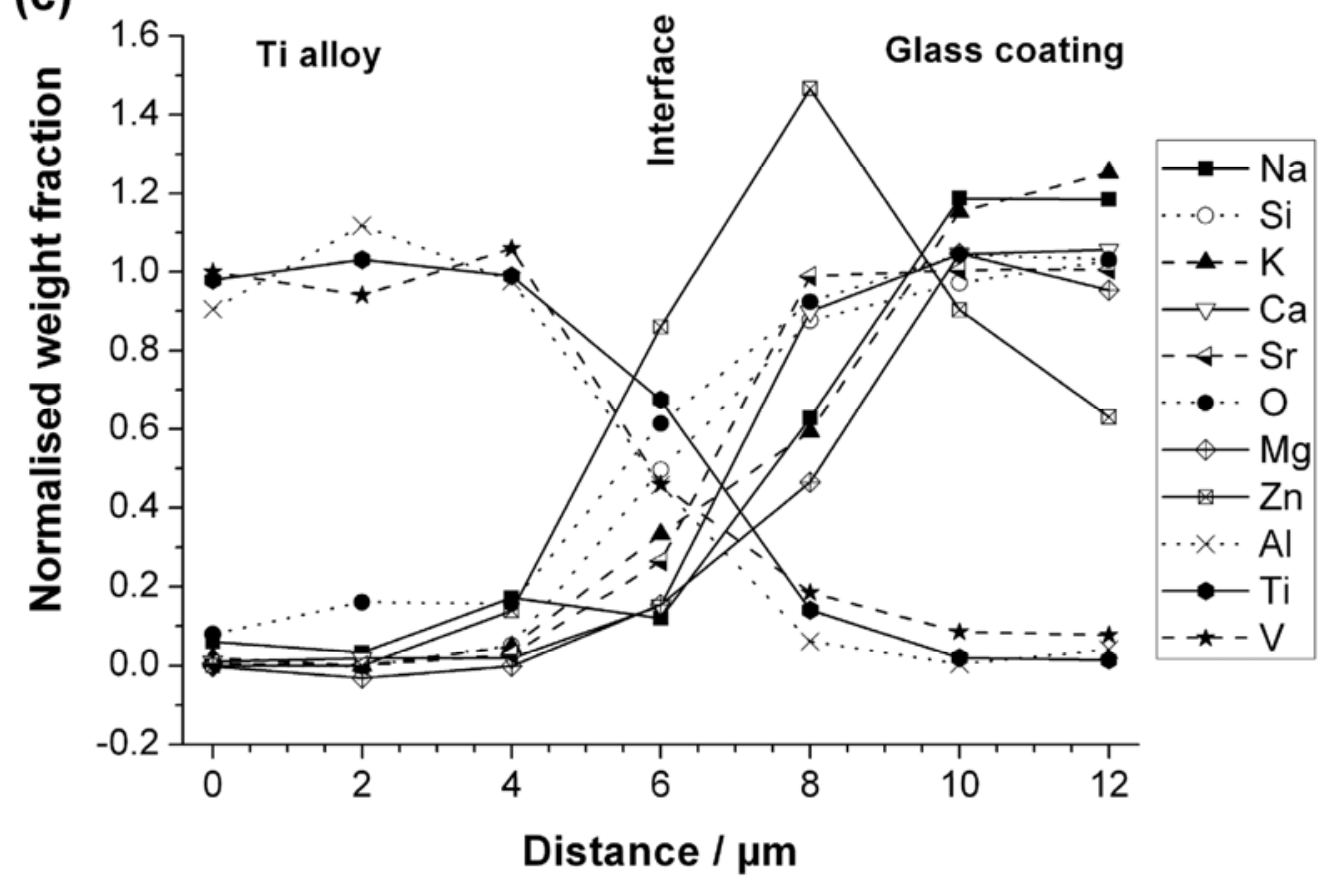

Figure11: Line scan profile across the interface between Ti-alloy and 50\% Sr glass coating: (a), (b) SEM micrograph of area of scan and (c) normalised element concentrations. 


\section{Conclusion}

Bioactive glass coatings with a thermal expansion coefficient matched to Ti6Al4V alloy have been produced. Processing windows (i.e. the temperature range between glass transition temperature and the onset of crystallisation) are significantly increased compared to Bioglass ${ }^{\circledR} 45 \mathrm{~S} 5$. Substituting strontium for calcium in the glass composition reduces the glass transition temperature and lowers the activation energy for crystallisation whilst increasing the onset temperature of crystallisation. The mixed calcium/strontium glasses exhibit a larger processing window (200 K and more), which favours sintering without crystallisation occurring to obtain amorphous well sintered coatings. However the glass with complete strontium substitution favours crystallisation due to a smaller processing window.

\section{References}

[1] L. L. Hench, J. Wilson. An introduction to bioceramics. World Scientific Publishing Co. Pte. Ltd; 1993.

[2] L. L. Hench. Journal of the American Ceramic Society 74 (1991) 1487.

[3] L. L. Hench, P. J. Buscemi, inventors; Board of Regents SoFTF, assignee. Bioglass coated metal substrate. US patent 4234972. 1980.

[4] J. M. Gomez-Vega, E. Saiz, A. P. Tomsia. Journal of Biomedical Materials Research 46 (1999) 594.

[5] J. M. Gomez-Vega, E. Saiz, A. P. Tomsia, G. W. Marshall, S. J. Marshall. Biomaterials 21 (2000) 105.

[6] D. C. Clupper, L. L. Hench. Journal of Non-Crystalline Solids 318 (2003) 43.

[7] R. G. Hill. Journal of Materials Science Letters 15 (1996) 1122.

[8] S. Foppiano, S. J. Marshall, E. Saiz, A. P. Tomsia, G. W. Marshall. Acta Biomaterialia 2 (2006) 133.

[9] J. M. Gomez-Vega, E. Saiz, A. P. Tomsia, T. Oku, K. Suganuma, G. W. Marshall, et al. Advanced Materials 12 (2000) 894.

[10] I. Elgayar, A. Aliev, A. R. Boccaccini, R. G. Hill. Journal of Non-Crystalline Solids 351 (2005) 173.

[11] D. S. Brauer, N. Karpukhina, R. V. Law, R. G. Hill. Journal of Materials Chemistry 19 (2009) 5629.

[12] M. D. O'Donnell, S. J. Watts, R. V. Law, R. G. Hill. Journal of Non-Crystalline Solids 345 (2008) 3554.

[13] A. Tilocca, A. N. Cormack, N. H. de Leeuw. Faraday Discussions 136 (2007) 45.

[14] A. Tilocca, A. N. Cormack. Journal of Physical Chemistry B 111 (2007) 14256.

[15] A. Tilocca. Physical Review B 76 (2007) 224202. 
[16] M. D. O'Donnell, S. J. Wattsa, R. V. Law, R. G. Hill. Journal of Non-Crystalline Solids 345 (2008) 3554.

[17] S. J. Watts, R. G. Hill, M. D. O'Donnell, R. V. Law. Influence of magnesia on the structure and properties of bioactive glasses. Journal of Non-Crystalline Solids. In press 2009.

[18] L. Linati, G. Lusvardi, G. Malavasi, L. Menabue, M. C. Menziani, P. Mustarelli, et al. Journal of Physical Chemistry B 109 (2005) 4989.

[19] A. Dietzel. Z Elektrochem Angew Phys Chem 48 (1942) 9.

[20] H. Arstila, E. Vedel, L. Hupa, M. Hupa. Journal of the European Ceramic Society 27 (2007) 1543.

[21] H. Arstila, L. Hupa, K. H. Karlsson, M. Hupa. Journal of Non-Crystalline Solids 354 (2008) 722.

[22] P. J. Marie, P. Ammann, G. Boivin, C. Rey. Calcified Tissue International 69 (2001) 121.

[23] P. J. Marie. Current Opinion in Pharmacology 5 (2005) 633.

[24] Cable M. Glasses \& Amorphous Materials Zorzycki,J. (Ed) Vol.9 of. "Materials Science \& Technology, A Comprehensive treatment",Cahn, R.W., Haasen, P., Kromer, E.J. VCH Publishers Inc., Weinheim; 1991. p. 22-31.

[25] O. H. Andersson. Journal of Materials Science: Materials in Medicine 3 (1992) 326.

[26] K. Aida, T. Komatsu, V. Dimitrov. Physics and Chemistry of Glasses 42 (2001) 103.

[27] A. B. G. Lansdown, U. Mirastschijski, N. Stubbs, E. Scanlon, M. S. Agren. Wound Repair and Regeneration 15 (2007) 2.

[28] M. Yamaguchi, R. Yamaguchi. Biochemical Pharmacology 35 (1986) 773.

[29] M. Yamaguchi, H. Oishi, Y. Suketa. Biochemical Pharmacology 36 (1987) 4007.

[30] P. J. Marie. Osteoporos Int 16 Suppl 1 (2005) S7.

[31] F. Dabsie, G. Gregoire, M. Sixou, P. Sharrock. Journal of Dentistry 37 (2009) 554.

[32] Y. Fredholm, N. Karpukhina, R. V. Law, R. G. Hill. Strontium containing bioactive glasses: glass structure and physical properties (submitted). Journal of Non-Crystalline Solids. In press 2009.

[33] A. Marotta, A. Buri, F. Branda. Journal of materials science 16 (1981).

[34] K. E. Wallace, R. G. Hill, J. T. Pembroke, C. J. Brown, P. V. Hatton. Journal of Materials Science: Materials in Medicine 10 (1999) 697.

[35] X. Chatzistavrou, T. Zorba, K. Chrissafis, G. Kaimakamis, E. Kontonasaki, P. Koidis, et al. Journal of Thermal Analysis and Calorimetry 85 (2006) 253. 